\title{
Analysis of A Uniform Bernoulli - Euler Beam on Winkler Foundation Subjected to Harmonic moving load
}

\author{
*JIYA, M; SHABA, AI \\ Department of Mathematics, Federal University of Technology, Minna, 23401, Nigeria \\ Email: Jiyason@yahoo.com, proabelshaba@yahoo.com
}

\begin{abstract}
This paper established Galerkin Finite element method coupled with Newmark Beta time integration method to analyze Winkler foundation subjected to a harmonic moving load on a uniform Bernoulli - Euler Beam. MATLAB software was used to implement the Newmark time integration method to obtain the Analysis. The deflection of the Beam increase when the acceleration of the load was change from $a_{m}=2 \mathrm{~m} / \mathrm{s}^{2}$ to $a_{m}=15 \mathrm{~m} / \mathrm{s}^{2}$. Also when the position of the load was change from $n=5$ to $n=10$. It was observed from the results that the position of the load and the acceleration of the moving load affect the deflection of the Beam.
\end{abstract}

DOI: https://dx.doi.org/10.4314/jasem.v22i3.13

Copyright: Copyright $\odot 2017$ Jiya and Shaba. This is an open access article distributed under the Creative Commons Attribution License (CCL), which permits unrestricted use, distribution, and reproduction in any medium, provided the original work is properly cited

Dates: Received 14 December 2018; Received: 21February 2018; Accepted 09 March 2018

Keywords: FEM; Dynamics; Newmark; Harmonic; Matrices; Beam

A lot of engineering structures under moving loads get cracked during their life span. The applications of these structures have many magnitude of application in almost every field. This effect appears due to over stressing or during dynamic load. Understanding relationship between deflection and load on these structures is of high practical important to engineers. There has been a continuous flow of important contributions resulting in a vast body of literature on Dynamic analysis of Beam. Mehmood (2015) analysed Dynamic response of frame structures under a moving point load. Direct time integration method coupled with Galerkin method was used in the analysis. Fryba (1972) is also an excellent literature on Dynamic analysis of Beam. Following the same approach, Mermertas (1998) examines the interaction between curved bridge deck and a vehicle assuming to have four (4) degree of freedom. Different researchers have investigated Uniform Bernoulli - Euler Beam with different load type such as Senapl et al. (2010), Bong-Jo and YongSik (2012), Ogunyebi and Sunday (2012), Vlada et al. (2013).

Kien and Ha (2011) studied Dynamic characteristic a uniform Beam subjected to a moving load and axial force on a Winkler foundation. Galerkin method and Newmark time integration was used to obtained the Dynamic response. The result obtained showed that the magnificent factor was reduced during acceleration motion by the effect of resonance but increase during decelerated motion. In this work, the speed of the moving load is taken to vary with acceleration and the deflection of the load along longitudinal axis of the beam is also considered which make the degree of freedom at each node to be three (3). The objective of this research work was to investigate the effect of acceleration of load, velocity of load and position of the load on a Uniform Bernoulli - Euler Beam of a Winkler Foundation subjected to Harmonic moving load.

\section{MATERIAL AND METHODS}

Figure 1 below shows a simply supported Bernoulli - Euler Beam on a Winkler foundation with an accelerating load. The load moves from left to right in a variable speed

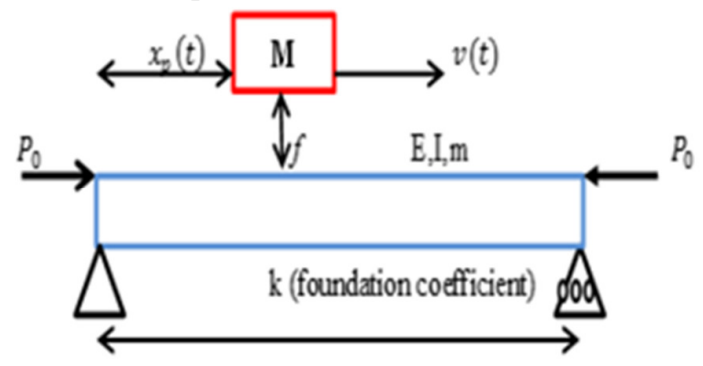

Fig. 1: A uniform beam with pinned-pinned support on a Winkler foundation under a moving point load

A Bernoulli - Euler Beam equation under Eccentric axial force and a moving point load is as 


$$
E l \frac{\partial^{4} w(x, t)}{\partial x^{4}}+m \frac{\partial^{2} w(x, t)}{\partial t^{2}}-P_{0} \frac{\partial^{2} w(x, t)}{\partial x^{2}}+k w(x, t)=P(x, t)
$$

In the above model, one parameter $k$ was used to model the elastic support based on the classical Winkler model.

The initially condition of the Beam at rest is given as:

$$
\left.\begin{array}{c}
w(x, 0)=0 \\
w(x, 0)=\frac{\dot{\partial \dot{w}(x, 0)}}{\partial t}=0
\end{array}\right\}
$$

And Boundary condition

$$
\left.\left.\begin{array}{c}
w(0, t)=0 \\
w(L, t)=0 \\
E I \frac{\partial^{2} w(x, t)}{\partial x^{2}}-M_{p}=0 \\
E I \frac{\partial^{3} w(x, t)}{\partial x^{3}}-V_{p}=0
\end{array}\right\} \text { at } x=0 \text { and } x=L\right\}
$$

The external load $P(x, t)$ in (1) is defined using Green's function as:

$P(x, t)=f \cos \theta t \delta\left(x-x_{p}(t)\right)$
Beam when the effect of inertia of the moving loads is considered given by the Newton's second law as:

$f=M\left(g-\frac{d^{2} w\left(x_{p}(t), t\right)}{d t^{2}}\right)$

Substituting $e q(5)$ into $e q(4)$ gives the transverse force between the moving load and the Beam, induced by the vibration of the Beam as

$$
P(x, t)=M\left(g-\frac{d^{2} w\left(x_{p}(t), t\right)}{d t^{2}}\right) \cos \theta t \delta\left(x-x_{p}(t)\right)
$$

Also the longitudinal force between the accelerating load and the beam, induced by the vibration as

$$
P(x, t)=M\left(a_{m}-\frac{d^{2} w\left(x_{p}(t), t\right)}{d t^{2}}\right) \cos \theta t \delta\left(x-x_{p}(t)\right)
$$

The total differential of the function $w\left(x_{p}(t), t\right)$ with respect to time $t$, with variable contact point $x$ is computed as

$$
\frac{d^{2} w\left(x_{p}(t), t\right)}{d t^{2}}=\frac{\partial^{2} w(x, t)}{\partial t^{2}}+2 \frac{\partial^{2} w(x, t)}{\partial x \partial t} \frac{d x_{p}(t)}{d t}+\frac{\partial^{2} w(x, t)}{\partial x^{2}}\left(\frac{d x_{p}(t)}{d x}\right)^{2}+\frac{\partial w(x, t)}{\partial x} \frac{d^{2} x_{p}(t)}{d t^{2}}
$$

Where

$$
\begin{aligned}
& x_{p}(t)=x_{0}+v_{0} t+\frac{a_{m} t^{2}}{2} \\
& \frac{x_{p}(t)}{d t}=v(t)=v_{0}+a_{m} t \\
& \frac{x_{p}(t)}{d t^{2}}=a_{m}
\end{aligned}
$$

Substitute (10) \& (11) into (8), we have

$$
\begin{gathered}
\frac{d^{2} w\left(x_{p}(t), t\right)}{d t^{2}}=\frac{\partial^{2} w(x, t)}{\partial t^{2}}+2 v \frac{\partial^{2} w(x, t)}{\partial x \partial t}+(v)^{2} \frac{\partial^{2} w(x, t)}{\partial x^{2}} \\
+a_{m} \frac{\partial w(x, t)}{\partial x}
\end{gathered}
$$

Finite Element Discretization: We need to introduce expression for the shape function $N_{i}$ to be able calculate the nodal load vector, mass matrices and stiffness matrices

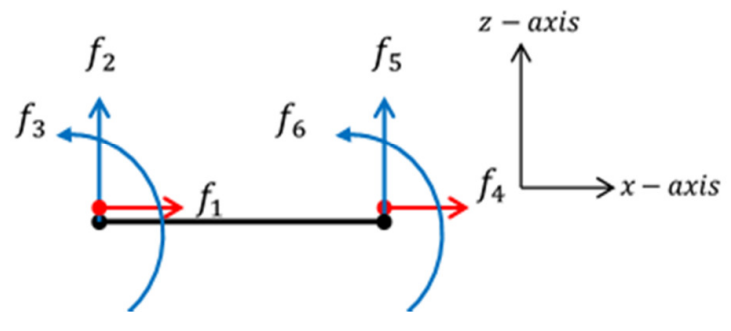

Fig 2. A uniform Beam element and its nodal degree of freedom.

Let assumed the axial displacement of the Beam for the longitudinal vibration to be linear, so the shape functions for the longitudinal vibration along $x-$ axis is given as

$w_{x}=N_{i} C_{i}=N_{1} C_{1}+N_{4} C_{4}=\left[\begin{array}{ll}N_{1} & N_{4}\end{array}\right]\left\{\begin{array}{l}C_{1} \\ C_{4}\end{array}\right\} \quad, i=1,4$

Where

$N_{1}=1-\frac{x}{l}$

$N_{4}=\frac{x}{l}$

For the transverse displacement and rotation along the $z$-axis, we use cubic interpolating function known as Hermite cubic polynomial for our shape function given as

$$
w_{z}=N_{i} C_{i}=N_{2} C_{2}+N_{3} C_{3}+N_{5} C_{5}+N_{6} C_{6}, \quad i=2,3,5,6
$$

$$
w_{z}=\left[\begin{array}{llll}
N_{2} & N_{3} & N_{5} & N_{6}
\end{array}\right]\left\{\begin{array}{l}
C_{2} \\
C_{4} \\
C_{5} \\
C_{6}
\end{array}\right\}
$$

Where

$$
\begin{aligned}
& N_{2}=x-\frac{2 x^{2}}{l^{2}}+\frac{x^{3}}{l^{3}} \\
& N_{3}=1-\frac{3 x^{2}}{l}+\frac{2 x^{3}}{l^{3}}
\end{aligned}
$$

Jiya, M; Shaba, AI 
$N_{5}=\frac{3 x^{2}}{l^{2}}-\frac{2 x^{3}}{l^{3}}$
$N_{6}=-\frac{x^{2}}{l}+\frac{x^{3}}{l^{2}}$

The assumed displacement for each element is given as

$$
\int_{0}^{l}[N]^{T}\left(E I \frac{\partial^{4} w(x, t)}{\partial x^{4}}+m \frac{\partial^{2} w(x, t)}{\partial t^{2}}-P_{0} \frac{\partial^{2} w(x, t)}{\partial x^{2}}+k w(x, t)-P(x, t)\right) d x=0
$$

After some integration and applying the Boundary conditions gives,

$$
\begin{gathered}
\int_{0}^{l}\left[\frac{d^{2} N}{d x^{2}}\right]^{T} E I \frac{\partial^{2} w(x, t)}{\partial x^{2}} d x+\int_{0}^{l}[N]^{T} m \frac{\partial^{2} w(x, t)}{\partial t^{2}} d x-\int_{0}^{l}\left[\frac{d N}{d x}\right]^{T} P_{0} \frac{\partial^{2} w(x, t)}{\partial x^{2}} d x-\left.P_{0}[N]^{T} \frac{\partial w(x, t)}{\partial x}\right|_{0} ^{l} \\
+\int_{0}^{l}[N]^{T} k w(x, t) d x-\int_{0}^{l}[N]^{T} P(x, t) d x=0
\end{gathered}
$$

Assembling the elements we have

$$
\begin{gathered}
\sum_{j=1}^{n}\left\{\int_{0}^{l}\left[\frac{d^{2} N}{d x^{2}}\right]^{T} E I \frac{\partial^{2} w(x, t)}{\partial x^{2}} d x+\int_{0}^{l}[N]^{T} m \frac{\partial^{2} w(x, t)}{\partial t^{2}} d x-\int_{0}^{l}\left[\frac{d N}{d x}\right]^{T} P_{0} \frac{\partial^{2} w(x, t)}{\partial x^{2}} d x-\left.P_{0}[N]^{T} \frac{\partial w(x, t)}{\partial x}\right|_{0} ^{l}\right. \\
\left.+\int_{0}^{l}[N]^{T} k w(x, t) d x-\int_{0}^{l}[N]^{T} P(x, t) d x=0\right\}
\end{gathered}
$$

$n$ is the number of elements considered.

Therefore, $e q(25)$ becomes

$$
\begin{gathered}
\sum_{j=1}^{n}\left\{\int_{0}^{l}\left[N^{\prime \prime}\right]^{T} E I[N]^{\prime \prime}\{C\} d x+\int_{0}^{l}[N]^{T} m\{\ddot{C}\} d x-\int_{0}^{l}\left[N^{\prime}\right]^{T} P_{0}\left[N^{\prime}\right]\{C\} d x-\left.P_{0}[N]^{T}\left[N^{\prime}\right]\{C\}\right|_{0} ^{l}\right. \\
\left.+\int_{0}^{l}[N]^{T} k[N]\{C\} d x-\int_{0}^{l}[N]^{T} P(x, t) d x=0\right\}
\end{gathered}
$$

Substituting eq(6), (7) and (12) into (26) we have

$$
\begin{aligned}
& \sum_{j=1}^{n}\left\{\int_{0}^{l}\left[N^{\prime \prime}\right]^{T} E I[N]^{\prime \prime}\{C\} d x+\int_{0}^{l}[N]^{T} m\{\ddot{C}\} d x-\int_{0}^{l}\left[N^{\prime}\right]^{T} P_{0}\left[N^{\prime}\right]\{C\} d x-\left.P_{0}[N]^{T}\left[N^{\prime}\right]\{C\}\right|_{0} ^{l}\right. \\
& +\int_{0}^{l}[N]^{T} k[N]\{C\} d x \\
& -\int_{0}^{l}[N]^{T}\left\{M\left(g-\left(\frac{\partial^{2} w(x, t)}{\partial t^{2}}+2 v \frac{\partial^{2} w(x, t)}{\partial x \partial t}+(v)^{2} \frac{\partial^{2} w(x, t)}{\partial x^{2}}+a_{m} \frac{\partial w(x, t)}{\partial x}\right)\right) \cos \theta t \delta\left(x-x_{p}(t)\right)\right\} d x \\
& =0\} \\
& \text { (27) } \\
& \sum_{j=1}^{n}\left\{\int_{0}^{l}\left[N^{\prime \prime}\right]^{T} E I[N]^{\prime \prime}\{C\} d x+\int_{0}^{l}[N]^{T} m\{\ddot{C}\} d x-\int_{0}^{l}\left[N^{\prime}\right]^{T} P_{0}\left[N^{\prime}\right]\{C\} d x-\left.P_{0}[N]^{T}\left[N^{\prime}\right]\{C\}\right|_{0} ^{l}\right. \\
& +\int_{0}^{l}[N]^{T} k[N]\{C\} d x \\
& -\int_{0}^{l}[N]^{T}\left\{M\left(a_{m}-\left(\frac{\partial^{2} w(x, t)}{\partial t^{2}}+2 v \frac{\partial^{2} w(x, t)}{\partial x \partial t}+(v)^{2} \frac{\partial^{2} w(x, t)}{\partial x^{2}}+a_{m} \frac{\partial w(x, t)}{\partial x}\right)\right) \cos \theta t \delta\left(x-x_{p}(t)\right)\right\} d x \\
& =0\}
\end{aligned}
$$

And can be simplified and written in familiar way as:

$[M]\{\ddot{C}\}+[D]\{\dot{C}\}+[K]\{C\}=F$

Where

$[M]=\sum_{J=1}^{N}\left\{\int_{0}^{l} m[N]^{T}[N]\{C\} d x-\int_{0}^{l}[N]^{T} M \cos \theta t[N]\{C\}\right\}$

Jiya, M; Shaba, AI 


$$
\begin{aligned}
{[D]=\sum_{J=1}^{N}\left\{-\int_{0}^{l}[N]^{T} M\right.} & \left.\cos \theta t 2\left(v_{0}+a_{m}\right)\left[N^{\prime}\right]\{\dot{C}\} \delta\left(x-x_{p}(t)\right) d x\right\} \\
{[K]=\sum_{j=1}^{n}\{} & \left\{\int_{0}^{L} E I\left[N^{\prime \prime}\right]^{T}\left[N^{\prime \prime}\right]\{C\} d x\right. \\
& +\int_{0}^{l} P_{0}\left[N^{\prime}\right]^{T}\left[N^{\prime}\right]\{C\} d x-P_{0}[N]^{T}\left[N^{\prime}\right]\{C\} \\
& +\int_{0}^{l} k[N]^{T}[N]\{C\} d x \\
& \left.-\int_{0}^{l}[N]^{T} M \cos \theta t\left(v_{0}+a_{m} t\right)^{2}\left[N^{\prime \prime}\right]\{C\} \delta\left(x-x_{p}(t)\right) d x+\int_{0}^{l}[N]^{T} M \cos \theta t a_{m}\left[N^{\prime}\right]\{C\} \delta\left(x-x_{p}(t)\right) d x\right\}
\end{aligned}
$$

$[M]$ Represent the overall mass matrix;

$[C]$ Represent the overall damping matrix;

$[K]$ Represent the overall Stiffness matrix;

$\{\ddot{C}\}$ Represent the acceleration, Vector of the system;

$\{\dot{C}\}$ Represent the Velocity Vector of the system;

$\{C\}$ Represent the Displacement Vector of the system

For lateral and rotation deflection

$F=\sum_{j=1}^{n}\left\{\int_{0}^{l}[N]^{T} M \cos \theta \operatorname{tg} \delta\left(x-x_{p}(t)\right)\right\}$

and for axial deflection.

$F=\sum_{j=1}^{n}\left\{\int_{0}^{l}[N]^{T} M \cos \theta t a_{m} \delta\left(x-x_{p}(t)\right)\right\}$

The equation of motion (19) can be solved for solution of displacement, velocity and acceleration at time $t+\Delta t$ by using Numerical time integration method. Beta time integration method was used with $\alpha=\frac{1}{2}$ and $\beta=\frac{1}{4} \quad$ (average acceleration). Because numerical procedure produce stability issue, using an unconditionally stable method is practical. Average acceleration method is unconditionally stable and does not have numerical damping

\section{RESULT AND DISCUSSION}

The results of the equation of motion of Bernoulli Euler Beam on Winkler Foundation are present graphically in the Figure below. MATLAB software was used to obtain the mass matrix, stiffness matrices and damping matrix. Newmark Beta integration method is implemented in the MATLAB software to solve the equation. The following values were used for simulation of the results. $L=$ $1000, l=20 m, n=50$ element, $E=30 \times$ $10^{9} / m^{2}, I=0.0234 m^{4}$

$g=9.81 \mathrm{~m} / \mathrm{s}^{2}, \mathrm{~m}=1000 \mathrm{~kg} / \mathrm{m}, M=2000 \mathrm{~kg}$, $k=4 \times 10^{5} \mathrm{~N} / \mathrm{m}^{2}$ (a sandy - clay foundation $)$

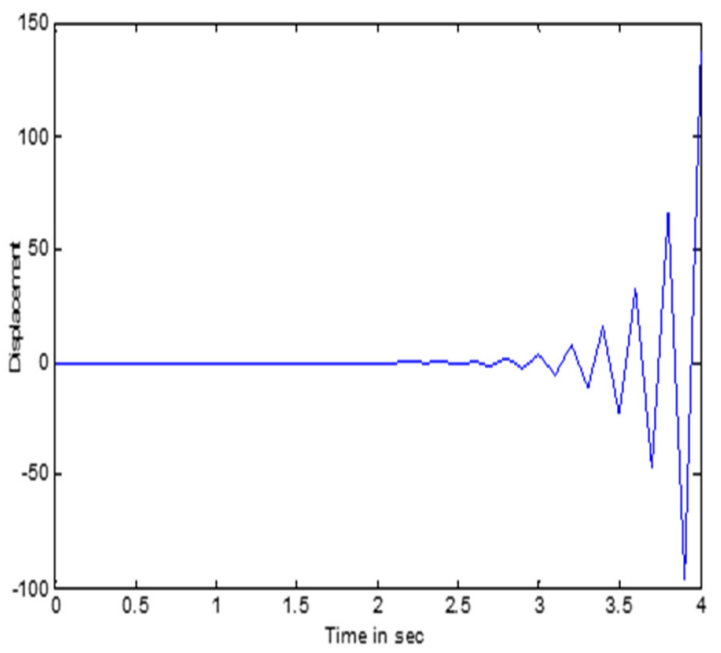

Fig 1a. Beam deflection without elastic support with $\theta=$ $10 \mathrm{rads}, k=0 \mathrm{~N} / \mathrm{m}^{2}, a_{m}=2 \mathrm{~m} / \mathrm{s}^{2}, v_{0}=20 \mathrm{~m} / \mathrm{s}, n=4, P_{0}=0$

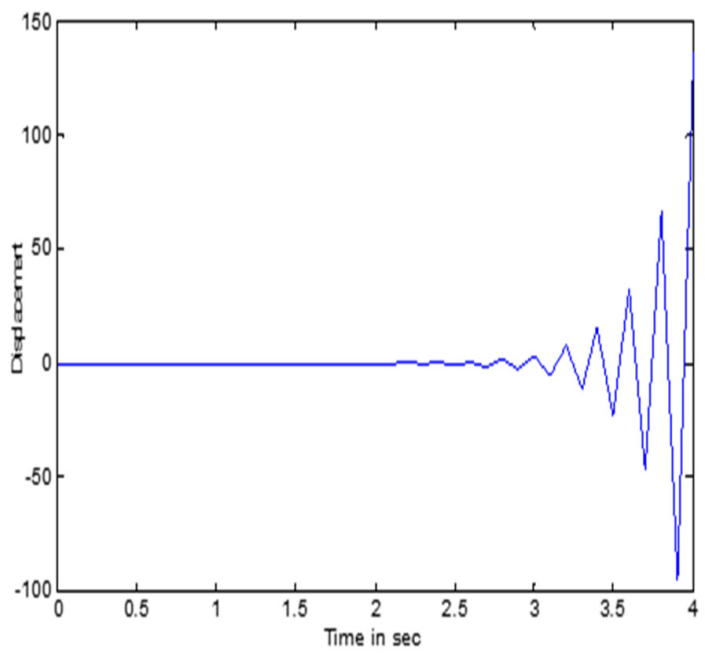

Fig 1b. Beam deflections with elastic support with $\theta=$ $10 \mathrm{rads}, k=4 \times 10^{5} \mathrm{~N} / \mathrm{m}^{2}, a_{m}=2 \mathrm{~m} / \mathrm{s}^{2}, v_{0}=20 \mathrm{~m} / \mathrm{s}, n=$ $4, P_{0}=0$

Jiya, $M ;$ Shaba, AI 


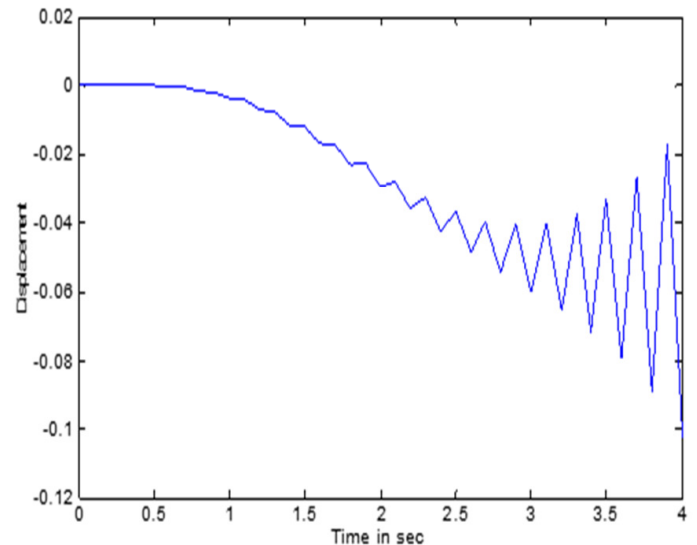

Fig 2.a. Beam deflection with increase velocity with $\theta=$ $10 \mathrm{rads}, k=4 \times 10^{5} \mathrm{~N} / \mathrm{m}^{2}, a_{m}=8 \mathrm{~m} / \mathrm{s}^{2}, v_{0}=20 \mathrm{~m} / \mathrm{s}, n=$ 5, $P_{0}=25.7275$



Fig 2.b. Beam deflections with increase velocity with $\theta=$ 10 rads, $k=4 \times 10^{5} \mathrm{~N} / \mathrm{m}^{2}, a_{m}=8 \mathrm{~m} / \mathrm{s}^{2}, v_{0}=60 \mathrm{~m} / \mathrm{s}, n=$ $5, P_{0}=25.7275$

Figure 1 both (a) and (b) shows the effect of elastic support on the deflection of the Beam. The behaviour of the graph in Figure 1 (a) and (b) shows that as the coefficient of the foundation stiffness is varied from $k=0$ to $k=4 \times 10^{5} \mathrm{~N} / \mathrm{m}^{2}$ the frequency of the deflection gradually increases. The behaviour of the beam deflection is in conformity with the work of Kien and Ha (2011). Figure 2 (a) and (b) shows graphically the effect of increase in initial velocity on the deflection of the beam. When the initial velocity was $v_{0}=20 \mathrm{~m} / \mathrm{s}$ in Figure 2 (a) the amplitude of deflection of the Beam is higher as when compare with increase initial velocity to $v_{0}=60 \mathrm{~m} / \mathrm{s}$

Conclusion: From the finding of this work, we conclude as follows: The elastic support of foundation when the axial force is zero affects the deflection of the beam, there is high effect on the deflection of the beam when the initial velocity of the moving load increases significantly, acceleration of the moving load over the beam, highly affects the dynamic response of the system.

\section{REFERENCES}

Bong-Jo, R; Yong-Sik, K (2012). Dynamic Response and Active Vibration Control of Beam Structures under a Travelling Mass. Retrieved on $10^{\text {th }}$ January, 2016 from Creative website Http://creativecommon.org/licences/by/3.0.

Fryba, L (1972). Vibration of Solids and Structures under Moving Loads. Research Institute of Transport

Kien, ND; Ha, LT (2011). Dynamic Characteristics of Elastically Supported Beam Subjected to a Compressive Axial Force and a Moving Load. Vietnam Journal of Mechanics. 33(2): 113 131.

Mehmood, A (2015). Using Finite Element Method Vibration Analysis of Frame Structure under Moving Load. International Journal of Mechanical Engineering and Robotic Research. 4(1): $50-65$.

Mermertas, V (1998). Dynamic Interaction between the Vehicle and Simply Supported Curved Bridge Deck. Computer Methods in Applied Mechanics and Engineering. 162: 125

Senapl, AD; Arikoglu, A; Ozkol, I; Dogan, VZ (2010). Dynamic Analysis of a Finite Length Euler - Bernoulli Beam (Linear and NonLinear) on a Viscoelastic Foundation to a Moving Concentrated Force. Journal of Mechanical Science and Technology. 24(10): 1957 - 1961.

Shaba, AI (2016). Dynamic Analysis of Bernoulli Euler Beam on a Winkler Foundation Subjected to a Moving Harmonic load. Unpublished Master's Thesis at Federal University of Technology, Minna.

Ogunyebi, S; Sunday, J (2012). On the Response of a Non- Uniform Beam Transverse by Mobile Distributed Loads. Global Journal of Science Frontier Research. 12(3): $1-8$.

Vlada, G; Zrnic, N; Milovanceric, M (2013). Consideration of Various Moving Loads Models in Structural Dynamics of Large Gantry Cranes. Faculty of Mechanical Engineering. 41(4): 311 $-316$. 